\title{
AVALIAÇÃO DA CHUVA DE SEMENTES EM ÁREAS DE RESTINGA EM DIFERENTES ESTÁGIOS DE REGENERAÇÃO ${ }^{1}$
}

\author{
Maurício Augusto Rodrigues ${ }^{2}$, Adelita Aparecida Sartori Paoli ${ }^{3}$, José Marcos Barbosa ${ }^{4}$ e Nelson \\ Augusto dos Santos Junior ${ }^{4}$
}

\begin{abstract}
RESUMO - Este estudo foi desenvolvido numa área de restinga localizada no Município de São Vicente (SP). O trabalho teve como objetivo avaliar a chuva de sementes em três condições diferentes de regeneração. Para tanto, foram selecionadas as seguintes condições: Floresta Alta de restinga em estágio médio de regeneração, uma área de clareira na mesma condição citada anteriormente e uma terceira em estágio inicial de regeneração. Em cada condição foram instalados 10 coletores de sementes confeccionados com madeira e tela sombrite $80 \%$ no fundo, mantidos a uma altura de $20 \mathrm{~cm}$ do solo. Foram avaliadas mensalmente, pelo período de um ano, as densidades de propágulos depositados nos coletores, sendo esses propágulos identificados e categorizados com base na sua síndrome de dispersão e na sua classe sucessional. Na Área de Floresta Alta de restinga foi realizado um levantamento fitossociológico de forma a identificar quais propágulos presentes na chuva poderiam ser oriundos dessas áreas. Foi verificado que as densidades de propágulos são relativamente baixas se comparadas com outras formações de florestas pluviais atlânticas, mas compatíveis com outros estudos realizados com a mesma formação vegetal considerada neste estudo. Com relação às síndromes de dispersão e classes sucessionais, houve predominância da síndrome zoocórica e de espécies de classes sucessionais secundárias. Os resultados permitem concluir que a área apresenta boa capacidade de manutenção da sua dinâmica sucessional.
\end{abstract}

Palavras-chave: Floresta Tropical Atlântica, Dispersão de sementes e Recuperação de áreas degradadas.

\section{EVALUATION OF SEED RAIN IN AREAS OF RESTINGA WITH DIFFERENTS REGENERATION STAGES}

\begin{abstract}
This study was conducted in an area of restinga in the municipality of São Vicente (SP). The study aimed to evaluate the seed rain in three different conditions of regeneration. Was selected the following conditions: High Forest of Restinga in the middle stage of regeneration, an area of clearing in the same condition mentioned above and a third in early stages of regeneration. In each condition were installed 10 seed collectors made of wood and screen with $80 \%$ of shade, supported to a height of $20 \mathrm{~cm}$ of soil. They were evaluated monthly for one year, the densities of seed deposited in the collector, these seedlings are identified and categorized based on their dispersion syndrome and successional classes. The Area of High Forest area was carried out a phytosociological survey to identify which seedlings present in the rain could be from these areas. It was found that the densities of seedlings are relatively low compared to other formations of the Atlantic rain forest, but consistent with other studies of the same type of vegetation used in the study. Regarding dispersal syndromes and successional classes, there was prevalence of the zoocoric syndrome and species of secondary successional classes. The results indicate that the area has good ability to maintain their succession dynamics.
\end{abstract}

Keywords: Atlantic Rain Forest, Seed dispersion e Restoration of degraded areas.

\footnotetext{
${ }^{1}$ Recebido em 03.06.2008 e aceito para publicação em 02.03.2010.

${ }^{2}$ Doutorado em andamento pela Universidade Júlio de Mesquita Filho, UNESP, Brasil. E-mail: <mar.ambiente@gmail.com>.

${ }^{3}$ Universidade Estadual Paulista Júlio de Mesquita Filho, UNESP, Brasil.

${ }^{4}$ Instituto de Botânica, IBT, Brasil.
} 


\section{INTRODUÇÃO}

O termo restinga geralmente é utilizado para caracterizar as planícies costeiras ou planícies litorâneas arenosas (SUGIYAMA, 1998; CARRASCO, 2003; TESSLER e GOYA, 2005). Souza et al. (2008), com base em ampla revisão de literatura, indicam características como: feição de linha da costa alongada, de natureza arenosa e de muito baixa amplitude, que tende a fechar reentrâncias costeiras, comuns nas diferentes designações para caracterizar as restingas. Entretanto, nos estudos ecológicos o termo restinga é utilizado para se referir a todos os tipos de vegetação estabelecidos nas planícies costeiras quaternárias, incluindo-se em alguns casos as formações vegetais encontradas nas baixas e médias encostas da Serra do Mar (SOUZA et al., 2008), com pouca riqueza de espécies, baixa produtividade e pequena complexidade, se comparadas a outras formações florestais (SCARANO, 2002; 2006).

Mesmo assim, as variações nas formações vegetais das restingas devem-se à diversidade de origem, topografia e condições ambientais das planícies arenosas, assim como a fatores de caráter sucessional, que propiciam a formação de muitos hábitats e, consequentemente, a existência de uma flora rica e variada (ARAÚJO, 1984; SUGIYAMA, 1998; LOPES 2007), apresentando, de maneira geral, aumento na complexidade da vegetação no sentido oceanocontinente (MANTOVANI, 2000; LOPES, 2007); e a floresta atlântica é a principal fonte de espécies ocorrentes nas restingas das regiões Sul e Sudeste brasileiras (SCHERER et al., 2005).

Por estarem estabelecidas sobre solos arenosos, altamente lixiviados e pobres em nutrientes, essas formações vegetacionais são muito frágeis e passíveis de perturbações, o que dificulta a recuperação das áreas degradadas (ARAÚJO e LACERDA 1987) e a obtenção de dados mais conclusivos que, segundo Rodrigues (2000), são escassos.

Um mecanismo intrínseco em comunidades como essa é a dispersão de sementes, considerada um dos processos demográficos-chave na vida das plantas, pois funciona como uma ponte unindo as fases de polinização com o recrutamento que levará ao estabelecimento de novas plantas adultas (HARPER, 1977).
A sobrevivência e dinâmica das florestas dependem, em grande parte, desse aporte de sementes determinado pela chuva de sementes, consequência da composição florística da área e de suas vizinhanças, da variação espacial e temporal de propágulos e do comportamento dos dispersores de sementes (HARPER, 1977).

Consequentemente, conhecer as características fitossociológicas da área de estudo é fundamental para o entendimento da chuva de sementes, já que, segundo Kent e Coker (1992), independentemente das abordagens utilizadas, as descrições da composição, estrutura e funcionamento são as principais ferramentas para o conhecimento da vegetação, componente dominante e mais acessível das comunidades ecológicas terrestres.

Dessa forma, torna-se fundamental entender a dinâmica da chuva de sementes nas várias fisionomias de restinga, sujeitas a diferentes fatores de degradação e em estágios de regeneração distintos. Partindo-se desta premissa, este estudo teve como objetivo avaliar a chuva de sementes em áreas de restinga em diferentes estágios de regeneração, de forma a inferir sobre o estado de cada uma delas, confrontando-se com os dados da fitossociologia.

\section{MATERIALE MÉTODOS}

O trabalho foi desenvolvido numa área pertencente à empresa mineradora STAF (Sociedade Técnica de Areias para Fundição Ltda.), situada a noroeste do cruzamento da Ferrovia FEPASA com a Rodovia Pedro Taques, altura do km 70, no local denominado Samaritá, Distrito do Município de São Vicente (SP), com as seguintes coordenadas de referência: S $23^{\circ} 57^{\prime} 3^{\prime \prime}$ e W 46 23'15', De acordo com a Resolução n 7 do CONAMA, de 23/07/1996, a vegetação ocorrente no local é caracterizada como Floresta Alta de Restinga.

De acordo com a classificação de Köppen, o clima da região é definido como tropical super úmido, Af (CEPAGRI, 2009). A região apresenta grande nebulosidade e altos índices pluviométricos, principalmente entre outubro e março, com valores médios anuais de chuva de $1.600 \mathrm{~mm}$ a $3.000 \mathrm{~mm}$. A umidade relativa do ar varia entre $65 \%$ e $97 \%$, e a temperatura nos meses quentes varia de $22^{\circ}$ a $34,4^{\circ} \mathrm{C}$ e nos meses frios, entre $13^{\circ} \mathrm{e}$ $27,6^{\circ} \mathrm{C}$, com média anual de $24,7^{\circ} \mathrm{C}$. 
A observação da chuva de sementes foi realizada em três diferentes áreas: Área1 (Floresta Alta de Restinga), Área 2 (Clareira na Floresta Alta de Restinga) e Área 3 (Restinga em Processo de Recuperação). Segundo informações da Gerência da STAF, as Áreas de estudo 1 e 2 foram os primeiros locais a serem minerados na propriedade, justamente por se encontrar ao lado da linha férrea, único meio de escoamento da produção na década de 1950. Consta, ainda, que a área sofreu processo de mineração por um período de 10 anos, de meados dos anos 1950 até meados dos anos de 1960 .

Em cada uma das três áreas foram instalados, a uma altura de $20 \mathrm{~cm}$ do solo, 10 coletores de sementes de 1,0 m x 1,0 m x 10,0 cm confeccionados com madeira e sombrite, totalizando 30 coletores. Esses coletores foram distribuídos ao acaso da seguinte forma: nas Áreas 1 e 3, os coletores foram dispostos seguindo-se um transecto longitudinal, alocados a cada $25 \mathrm{~m}$ ao longo da linha de transecção, em lados alternados, a uma distância de $10 \mathrm{~m}$ do eixo do transecto e no mínimo 20 m das bordas. Na Área 2, foi aberta uma clareira quadrada com dimensões de $10 \mathrm{~m}$ x $10 \mathrm{~m}$, subdividida em 100 subparcelas de $1 \mathrm{~m}^{2}$, totalizando-se 10 colunas com 10 linhas cada uma. Os coletores foram instalados ao acaso, sorteando-se o número da linha nas diferentes colunas.

Mensalmente, durante o período de um ano (de 10/2004 a 9/2005) todo o material recolhido nos coletores de chuva de sementes foi levado para a Unidade de Pesquisa e Tecnologia de Sementes do Instituto de Botânica de São Paulo, onde foi triado, separando-se manualmente as sementes do restante da serrapilheira (com o auxílio de uma lupa) em morfoespécies e quantificando-se as diferentes espécies ocorrentes em cada um dos coletores, individualmente e no total, para cada uma das três áreas. Após a triagem e quantificação, as sementes foram colocadas em potes de vidro individualizados por morfoespécie para posterior identificação. As espécies amostradas foram classificadas quanto à categoria sucessional (BUDOWSKY, 1965) e à síndrome de dispersão (PIJL, 1972).

A similaridade entre as áreas foi comparada utilizando-se o índice de Jaccard (MAGURRAN, 1988).

Para análise estrutural da vegetação, foi utilizado o método de parcelas (MUELLER-DUMBOIS e ELLENBERG, 1974), considerando-se parcelas de
10 x $10 \mathrm{~m}$. As parcelas foram delimitadas com estacas de bambu e fitilho. Em cada parcela foram considerados os indivíduos com perímetro do caule à altura do peito (PAP) igual ou superior a $10 \mathrm{~cm}$. Cada um dos indivíduos amostrados foi numerado com uma plaqueta de alumínio. O perímetro foi medido com fita métrica a 1,30 m do solo e a altura, estimada com o auxílio de uma vara telescópica.

A partir dos dados obtidos no campo, foram calculados os valores de importância, cobertura, frequência e densidades absolutas e relativas de cada espécie (MUELLER-DUMBOIS e ELLENBERG, 1974) e o índice de diversidade de Shannon e Weaner da comunidade (PIELOU, 1975).

\section{RESULTADOS}

Das 43 espécies encontradas na área de estudo, as primeiras 11 são responsáveis por $61,24 \%$ do total de indivíduos amostrados (Tabela 1). Essas mesmas espécies são as mais significativas com relação à \%IVI, somando nesse caso $62,09 \%$ do total, apresentando índice de diversidade e equabilidade elevados, respectivamente, $\mathrm{H}^{\prime}=3,335$ e $\mathrm{J}=0,887$.

Com relação ao padrão de distribuição vertical dos vários estratos encontrados nessa vegetação (Figura 1a), verificou-se alta concentração de indivíduos nas classes de altura variando de 2 a 4,5 m (37,83\%) e 5 a 7,5 m $(41,44)$, com algumas poucas espécies apresentando alturas iguais ou superiores a $10 \mathrm{~m}$.

O mesmo padrão pôde ser observado com relação à distribuição dos indivíduos em classes de PAP(Figura 1b), obtendo-se novamente a grande maioria dos indivíduos distribuídos nas duas primeiras classes, que variam de 10 a 17,5 cm (45,07\%) e 18 a 25 cm (20,72\%), refletindo, portanto, em reduzida fitomassa.

Foram amostradas nos coletores de chuva de sementes, nas três áreas, 16 famílias, sendo aquelas que apresentaram maior número de espécies Fabaceae, Lauraceae, Melastomataceae (todas representadas por três espécies), Annonaceae, Bignoniaceae, Euphorbiaceae, Myrsinaceae e Myrtaceae (todas representadas por duas espécies). As demais famílias foram representadas por apenas uma espécie, totalizando 29,62\% do total de espécies (Tabela 2).

Revista Árvore, Viçosa-MG, v.34, n.5, p.815-824, 2010 
Tabela 1 - Parâmetros fitossociológicos das espécies amostradas na floresta alta de restinga, Município de São Vicente, SP, organizadas segundo o Índice de Valor de Importância (IVI), em que DRe = Densidade Relativa; DoRe. = Dominância Relativa; FRe. $=$ Frequência Relativa; e AM = Altura Média.

Table 1 - Phytosociological parameters of the species in the High Forest of Restinga, in São Vicente / SP, organized according Value Index of Importance (IVI), where: Dre = Relative Density, Dore. = Relative Dominance, Fre. $=$ Relative Frequency and $A M=$ Average Height.

\begin{tabular}{|c|c|c|c|c|c|}
\hline Espécies & DRe & DoRe & FRe & IVI & $\mathrm{AM}$ \\
\hline Alchornea triplinervia (Spreng.) M. Arg. & 11,71 & 11,76 & 6,67 & 30,13 & 5,3 \\
\hline Tibouchina pulchra Cogn. & 9,91 & 14,94 & 5,00 & 29,85 & 5,8 \\
\hline Ocotea pulchella (Ness.) Mez & 9,91 & 12,27 & 6,67 & 28,85 & 6,4 \\
\hline Actinostemon concolor (Spreng.) Müll. Arg. & 7,21 & 6,41 & 5,00 & 18,61 & 7,3 \\
\hline Maytenus robusta Reissek & 4,50 & 11,72 & 1,67 & 17,89 & 6,2 \\
\hline Didimopanax angustissimum Marchal & 4,50 & 5,49 & 3,33 & 13,33 & 7,1 \\
\hline Miconia саbucu Hoehne & 1,80 & 3,29 & 3,33 & 8,43 & 7,0 \\
\hline Clusia criuva Cambess & 1,80 & 2,88 & 3,33 & 8,01 & 10,0 \\
\hline Pera glabrata (Schott) Baill. & 2,70 & 1,60 & 3,33 & 7,64 & 7,7 \\
\hline Ocotea aciplylla (Ness.) Mez. & 2,70 & 1,46 & 3,33 & 7,50 & 7,3 \\
\hline Gomidesia spectabilis (DC.) O. Berg. & 4,50 & 1,07 & 1,67 & 7,24 & 3,6 \\
\hline Licania nitida Hook. F & 1,80 & 3,74 & 1,67 & 7,21 & 8,5 \\
\hline Clethra scabra Pers. & 1,80 & 1,41 & 3,33 & 6,54 & 6,0 \\
\hline Ocotea elegans Mez. & 0,90 & 3,79 & 1,67 & 6,36 & 8,0 \\
\hline Tapirira guianensis Aubl. & 0,90 & 3,40 & 1,67 & 5,97 & 12,0 \\
\hline Abarema lusoria (Benth.) Barn. \& Grimes & 1,80 & 0,31 & 3,33 & 5,45 & 4,8 \\
\hline Erythroxylum amplifolium Baill. & 2,70 & 1,05 & 1,67 & 5,42 & 5,2 \\
\hline Geonoma schottiana Mart. & 2,70 & 0,99 & 1,67 & 5,36 & 2,8 \\
\hline Guapira opposita (Vell.) Reitz & 1,80 & 0,96 & 1,67 & 4,43 & 7,3 \\
\hline Andira anthelmia (Vell.) Macbr. & 1,80 & 0,89 & 1,67 & 4,36 & 3,8 \\
\hline Eugenia monosperma Vell. & 0,90 & 1,60 & 1,67 & 4,17 & 11,0 \\
\hline Pouteria caimito (Ruiz \& Pav) Radlk. & 1,80 & 0,65 & 1,67 & 4,12 & 4,5 \\
\hline Sorocea hillarii Gaudich. & 0,90 & 1,51 & 1,67 & 4,08 & 4,0 \\
\hline Eugenia florida DC. & 1,80 & 0,40 & 1,67 & 3,87 & 3,8 \\
\hline Miconia cubatanensis Hoehne & 0,90 & 0,98 & 1,67 & 3,55 & 7,0 \\
\hline Miconia dodecandra (Desr.) Cogn. & 0,90 & 0,73 & 1,67 & 3,30 & 3,5 \\
\hline Psidium cattleyanum Sabine & 0,90 & 0,62 & 1,67 & 3,18 & 6,0 \\
\hline Piptocarpha oblonga (Gardner) Backer & 0,90 & 0,62 & 1,67 & 3,18 & 4,5 \\
\hline Matayba juglandifolia Radlk. & 0,90 & 0,56 & 1,67 & 3,13 & 5,5 \\
\hline Miconia sp. & 0,90 & 0,44 & 1,67 & 3,01 & 6,0 \\
\hline Ocotea oppositifolia S. Yasuda & 0,90 & 0,38 & 1,67 & 2,95 & 5,0 \\
\hline Sloanea guianensis (Aubl.) Benth. & 0,90 & 0,25 & 1,67 & 2,81 & 5,0 \\
\hline Eugenia stigmatosa DC. & 0,90 & 0,23 & 1,67 & 2,80 & 6,0 \\
\hline Gomidesia anacardiaefolia (Gardner) O. Berg. & 0,90 & 0,23 & 1,67 & 2,80 & 7,0 \\
\hline Podocarpus sellowii Klotzsch & 0,90 & 0,20 & 1,67 & 2,76 & 4,5 \\
\hline Cabralea cangerana (Vell.) Mart. & 0,90 & 0,17 & 1,67 & 2,74 & 3,5 \\
\hline Tabebuia obtusifolia (Cham.) Bureau & 0,90 & 0,17 & 1,67 & 2,74 & 3,0 \\
\hline Pouteria beaurepairei (Glaz. \& Raunk.) Bae. & 0,90 & 0,17 & 1,67 & 2,74 & 4,0 \\
\hline Guateria hilariana Schltdl. & 0,90 & 0,14 & 1,67 & 2,71 & 3,5 \\
\hline Daphnopsis schwackeana Taub & 0,90 & 0,14 & 1,67 & 2,71 & 4,0 \\
\hline Ocotea sp. & 0,90 & 0,14 & 1,67 & 2,71 & 2,5 \\
\hline Croton sphaerogynus Baill. & 0,90 & 0,14 & 1,67 & 2,71 & 3,5 \\
\hline Eclinusa ramiflora Maer. & 0,90 & 0,12 & 1,67 & 2,68 & 3,5 \\
\hline
\end{tabular}

Verificou-se que as famílias mais representativas na chuva de sementes eram de espécies ocorrentes nas áreas de entorno dos experimentos, constatando-se que 44,4\% das espécies coletadas (12 espécies) nas Áreas 1 e 2 eram autóctones.

Revista Árvore, Viçosa-MG, v.34, n.5, p.815-824, 2010 
Tabela 2 - Listagem das famílias/espécies ocorrentes na chuva de sementes da Área 1 (Floresta Alta de Restinga), Área 2 (Clareira na Floresta Alta de Restinga) e Área 3 (Restinga em Processo de Recuperação), com as respectivas síndromes de dispersão e classes sucessionais, no Município de São Vicente, SP.

Table 2 - Families/species listing occurent in seed rain of the Area 1(High Forest of Restinga), Area 2 (Clearing of the High Forest of Restinga) e Area 3 (Recovery Process Restinga), with respectives dispersal syndromes and sucessional classes, in São Vicente, SP.

\begin{tabular}{|c|c|c|c|c|c|}
\hline \multirow[t]{2}{*}{ Famílias / Espécies } & \multicolumn{3}{|c|}{ Áreas } & \multirow{2}{*}{$\begin{array}{c}\text { Síndromes } \\
\text { de Dispersão }\end{array}$} & \multirow{2}{*}{$\begin{array}{c}\text { Classes } \\
\text { sucessionais }\end{array}$} \\
\hline & 1 & 2 & 3 & & \\
\hline \multicolumn{6}{|l|}{ Annonaceae } \\
\hline Guateria hilariana Schltdl. & & $\mathrm{x}$ & & Zoocórica & Secundária \\
\hline Xylopia sp. & & $\mathrm{x}$ & & Zoocórica & Secundária \\
\hline \multicolumn{6}{|l|}{ Aquifoliaceae } \\
\hline Ilex sp. & & $\mathrm{x}$ & & Zoocórica & Secundária \\
\hline \multicolumn{6}{|l|}{ Arecaceae } \\
\hline Geonoma schottiana Mart. & $\mathrm{x}$ & $\mathrm{x}$ & & Zoocórica & Secundária \\
\hline $\begin{array}{l}\text { Asteraceae } \\
\text { Baccharis singularis (Vell.) GMBarroso }\end{array}$ & & & $\mathrm{x}$ & Anemocórica & Pioneira \\
\hline \multicolumn{6}{|l|}{ Bignoniaceae } \\
\hline $\begin{array}{l}\text { Jacaranda puberula Cham. } \\
\text { Tabebuia obtusifolia (Cham.) Bureau }\end{array}$ & $\mathrm{x}$ & $\begin{array}{l}x \\
x\end{array}$ & & $\begin{array}{l}\text { Anemocórica } \\
\text { Anemocórica }\end{array}$ & $\begin{array}{l}\text { Secundária } \\
\text { Secundária }\end{array}$ \\
\hline \multicolumn{6}{|l|}{ Cecropiaceae } \\
\hline \multicolumn{6}{|l|}{ Clusiaceae } \\
\hline \multicolumn{6}{|l|}{ Elaeocarpaceae } \\
\hline \multicolumn{6}{|l|}{ Euphorbiaceae } \\
\hline $\begin{array}{l}\text { Alchornea triplinervia (Spreng.) M. Arg. } \\
\text { Pera glabrata (Schott) Baill. }\end{array}$ & $\begin{array}{l}\mathrm{x} \\
\mathrm{x}\end{array}$ & $\mathrm{x}$ & & $\begin{array}{l}\text { Zoocórica } \\
\text { Zoocórica }\end{array}$ & $\begin{array}{l}\text { Secundária } \\
\text { Secundária }\end{array}$ \\
\hline \multicolumn{6}{|l|}{ Fabaceae } \\
\hline Chamaecrista desvauxii (Collad.) Killip & & & $\mathrm{x}$ & Autocórica & Pioneira \\
\hline Clitoria laurifolia Poiret & & & $\mathrm{x}$ & Autocórica & Pioneira \\
\hline Inga sp. & & $\mathrm{x}$ & & Zoocórica & Pioneira \\
\hline \multicolumn{6}{|l|}{ Lauraceae } \\
\hline Ocotea aciplylla (Ness.) Mez. & $\mathrm{x}$ & & & Zoocórica & Secundária \\
\hline Ocotea oppositifolia S. Yasuda & $\mathrm{x}$ & & & Zoocórica & Secundária \\
\hline Ocotea pulchella (Ness.) Mez & $\mathrm{x}$ & $\mathrm{x}$ & & Zoocórica & Secundária \\
\hline \multicolumn{6}{|l|}{ Melastomataceae } \\
\hline Miconia cinnamomifolia (DC.) Naudin & $\mathrm{x}$ & & & Zoocórica & Secundária \\
\hline Tibouchina clavata (Pers.) Wurdack & & & $\mathrm{x}$ & Anemocórica & Pioneira \\
\hline Tibouchina pulchra Cogn. & $\mathrm{x}$ & $\mathrm{x}$ & & Anemocórica & Pioneira \\
\hline \multicolumn{6}{|l|}{ Myrsinaceae } \\
\hline Rapanea ferruginea (Ruiz \& Pav.) & & $\mathrm{x}$ & & Zoocórica & Pioneira \\
\hline Rapanea parvifolia (A. DC.) Mez & & $\mathrm{x}$ & & Zoocórica & Pioneira \\
\hline \multicolumn{6}{|l|}{ Myrtaceae } \\
\hline Eugenia sp. & & $\mathrm{x}$ & & Zoocórica & Secundária \\
\hline Gomidesia spectabilis (DC.) O. Berg. & $\mathrm{x}$ & & & Zoocórica & Secundária \\
\hline $\begin{array}{l}\text { Poaceae } \\
\text { Brachiaria decumbens Stapf. }\end{array}$ & & & $\mathrm{x}$ & Anemocórica & Pioneira \\
\hline $\begin{array}{l}\text { Rubiaceae } \\
\text { Diodia radula (Roem. \& Schult) Cham \& Schult. }\end{array}$ & & $\mathrm{x}$ & & Autocórica & Pioneira \\
\hline
\end{tabular}

Com relação à síndrome de dispersão, verificaram-se, respectivamente, na Área 1: 15,38\% de espécies anemocóricas e 84,62\% de zoocóricas; na Área 2: 20\% de anemocóricas, 15\% de autocóricas e 60\% de zoocóricas; e na Área 3: 60\% de anemocóricas e 40 de autocóricas. 

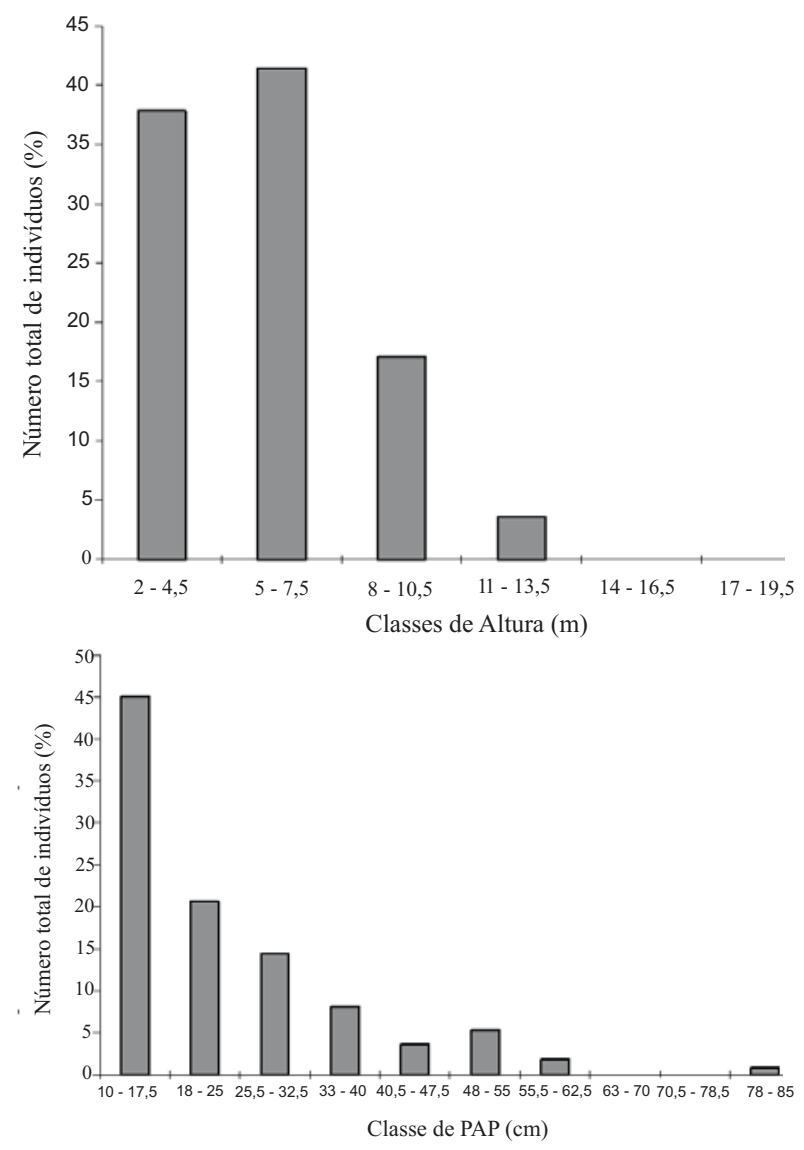

Figura 1 - a: Distribuição dos indivíduos amostrados na área de estudo por classes de altura; e b: distribuição dos indivíduos amostrados na área de estudo por classes de perímetro na altura do peito (PAP).

Figure 1 - a: Distribution of the individuals in the study area by height classes; and $b$ : distribution of the individuals in the study area for classes perimeter at breast height (PAP).

Quanto à classe sucessional das espécies, verificaram-se, respectivamente, na Área 1: 15,38\% de pioneiras e 84,62\% de secundárias; na Área 2: 37,5\% de pioneiras e 62,5\% de secundárias; e na Área 3: 100\% de espécies pioneiras.

Foram depositados no período um total de 2693 propágulos, correspondendo a uma densidade absoluta de 269,3 propágulos/m²; sendo 67,4 propágulos $/ \mathrm{m}^{2}$ na Área 1; 74,4 propágulos $/ \mathrm{m}^{2}$ na Área 2; e 127,5 propágulos $/ \mathrm{m}^{2}$ na Área 3.

Revista Árvore, Viçosa-MG, v.34, n.5, p.815-824, 2010
Quanto à distribuição temporal, observou-se que as sementes foram depositadas ao longo de todo o ano. Entretanto, verificou-se pico de deposição das sementes, que no geral ocorreu no período de outubro a março (Figura 2).

Entre as Áreas 1 e 2, observou-se um índice de similaridade igual a 31,81\%, com sete espécies em comum. Apenas Jacaranda puberula Cham. e Cecropia pachystachya Trécul não foram encontradas no estudo fitossociológico.

Analisando a similaridade florística das Áreas 1 e 2 em relação ao levantamento florístico realizado, foram verificados índices de similaridade, respectivamente, iguais a 21,73\% e 14,28\%. Das 27 espécies encontradas nos coletores de sementes, cinco foram exclusivas da Área 3, sendo todas autóctones. As demais espécies foram depositadas nos coletores das Áreas 1 e 2, sendo 10 alóctones (45,5\%); dessas, oito espécies eram zoocóricas (80\%), uma era anemocórica (10\%) e a outra, autocórica (10\%).

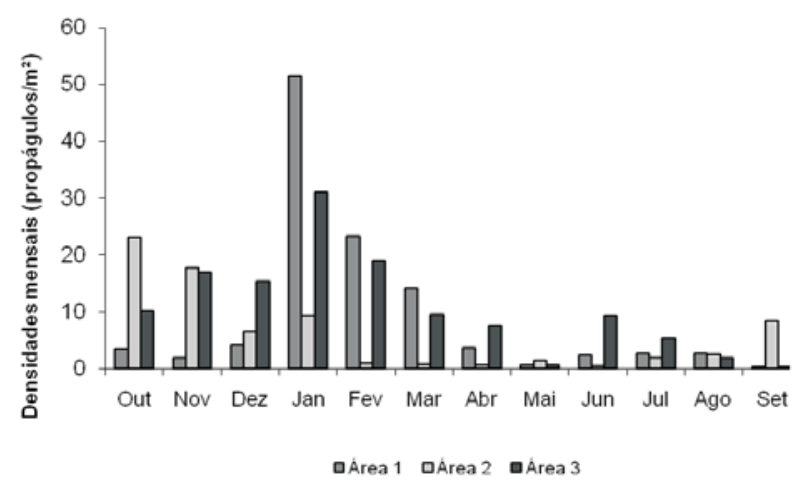

Tabela 2 - Listagem das famílias/espécies ocorrentes na chuva de sementes da Área 1 (Floresta Alta de Restinga), Área 2 (Clareira na Floresta Alta de Restinga) e Área 3 (Restinga em Processo de Recuperação), com as respectivas síndromes de dispersão e classes sucessionais, no Município de São Vicente, SP.

Table 2 - Families/species listing occurent in seed rain of the Area 1(High Forest of Restinga), Area 2 (Clearing of the High Forest of Restinga) $e$ Area 3 (Recovery Process Restinga), with respectives dispersal syndromes and sucessional classes, in São Vicente, SP. 


\section{DISCUSSÃO}

De forma geral, os resultados da fitossociologia estão muito próximos aos obtidos em outros levantamentos realizados em florestas de restinga ao longo do Estado de São Paulo (CÉSAR e MONTEIRO, 1995; SUGIYAMA, 1998; GUEDES e SILVA et al., 2005; CARRASCO, 2003; REIS-DUARTE, 2004; SILVA, 2006; SACRAMENTO et al., 2007), nos quais também foi verificada a predominância de Myrtaceae em número de espécies, podendo em alguns casos podendo formar praticamente uma comunidade exclusiva, conforme observado por Sugiyama (1998) no estudo realizado na Ilha do Cardoso, SP, onde se constatou que $45 \%$ dos indivíduos amostrados pertenciam a essa família.

De acordo com o histórico de ocupação da área, constata-se que ela sofreu interferência antrópica bastante intensa e, apesar de não ser manejada a pelo menos 50 anos, apresenta vegetação em estágio médio de regeneração (Resolução $n^{\circ} 7$ do CONAMA, de 23/07/ 1996). Isso pode ser explicado pelo fato de as três espécies com maiores valores de IVI serem consideradas heliófilas e apresentarem ampla ocorrência em áreas perturbadas, bem como em clareiras e bordas de matas (SÃO PAULO, 2005; TABARELLI e MANTOVANI, 1997).

Apesar de fortemente antropizada, a área em estudo apresentou diversidade de espécies considerada elevada, uma vez que o Índice de Diversidade de Shannon tende a variar de 1,5 a 3,5, sendo ainda menor em solos pouco férteis e com excesso de umidade (MARTINS, 1993). Com relação ao Índice de Equabilidade (J), o valor encontrado indica que as populações encontram-se distribuídas de forma homogênea na comunidade.

A avaliação das classes sucessionais, no estudo de chuva de sementes, indicou predominância elevada de espécies secundárias na Área 1, situação essa perfeitamente de acordo com o observado no estudo da fitossociologia, sendo constado que a vegetação se encontra em estágio médio de regeneração e, portanto, com número maior de espécies de classes sucessionais intermediárias. Na Área 2, foi verificado que a taxa de espécies secundárias apresentou valores mais elevados que na Área 1, ainda que menos pronunciados, e a taxa de espécies pioneiras também foi maior, o que provavelmente está relacionado à abertura do dossel, que facilitaria a chegada de sementes em quantidade maior, principalmente de espécies anemocóricas.
O predomínio de espécies zoocóricas verificado nas Áreas 1 e 2 é comum em florestas tropicais e de restinga (ALVES e METZGER, 2006; OLIVEIRA et al., 2001; PIVELLO et al., 2006), com ocorrência mínima de $50 \%$ até $75 \%$, na maioria dos trabalhos (HOWE e SMALLWOOD, 1982), e estão relacionadas a comunidades com menor grau de perturbação (JESUS et al., 2005).

Apesar de estarem situadas numa região sob forte pressão de degradação, a atividade de frugívoros é bastante intensa no fragmento, possibilitando a chegada de propágulos oriundos de outras localidades, garantindo, assim, a heterogeneidade florística desse fragmento. Outro fator favorável é a representatividade da família Fabaceae, muito importante para a recuperação de áreas litorâneas degradadas (CUNHA et al., 2003).

Na Área 3, por se tratar de área em processo de recuperação, com a vegetação exclusivamente composta por indivíduos arbustivo-herbáceos, 100\% das espécies coletadas são autóctones, o que reflete a diversidade baixa de espécies ocorrentes nesse local, bem como a grande fragilidade diante de novas perturbações. De acordo com Souza e Rodrigues (2005), a chuva de sementes em clareiras da floresta apresenta diferenças evidentes quando comparadas com as áreas abertas por perturbações antrópicas. Esses resultados se assemelham aos observados por Duncan e Chapmam (1999), estudando a chuva de sementes zoocóricas numa pastagem abandonada, com um remanescente no entorno. Esses pesquisadores verificaram que a maioria das sementes coletadas era de árvores e arbustos, que tipicamente crescem em pastagens perturbadas e em áreas de agricultura, não em clareiras na floresta.

Essa situação pode estar ocorrendo pelo fato de os dispersores de sementes evitarem áreas limpas, devido ao risco de predação (DUNCAN e CHAPMAM, 1999; JESUS et al., 2005). Dessa forma, a chuva de sementes pode estar correlacionada negativamente com a distância da borda da floresta (SOUZA e RODRIGUES, 2005).

Tallora e Morellato (2000) afirmaram que muitos estudos realizados em florestas tropicais mostram a presença de sazonalidade na produção de frutos. Neste estudo, verificou-se um pico de deposição de sementes nos meses de outubro a março, coincidindo com a época de umidade mais elevada na região, o que, segundo Morellato e Leitão-Filho (1992), são as épocas mais favoráveis para a dispersão e estabelecimento das espécies.

Revista Árvore, Viçosa-MG, v.34, n.5, p.815-824, 2010 
Comparando as densidades obtidas neste estudo com resultados de outros trabalhos realizados com chuva de sementes no Estado de São Paulo (SOUZA e RODRIGUES, 2005; BARBOSA e PIZO, 2006; VIEIRA e GANDOLFI, 2006), observou-se que os valores encontrados foram extremamente baixos, estando em maior conformidade com o estudo desenvolvido por Guedes et al. (2005), realizado no mesmo tipo de formação florestal.

Um dos principais fatores responsáveis pela densidade baixa de propágulos pode estar relacionado ao fato de a floresta ser formada, na sua grande maioria, por indivíduos jovens; assim, esses indivíduos ainda não apresentam máxima produção ou, não atingiram a idade reprodutiva.

\section{CONCLUSÕES}

O fragmento estudado encontra-se em estágio médio de regeneração, com predominância de espécies de classes sucessionais intermediárias e, apesar de apresentar índices de diversidade e equabilidade elevados, este ainda se encontra com elevado grau de antropização.

A maioria dos diásporos das espécies amostradas é alóctone, dos quais a grande parte é zoocórica, evidenciando-se que, apesar de a área ainda estar sob forte pressão antrópica, há intensa atividade de dispersores no local.

$\mathrm{Na}$ área em processo de regeneração não foi verificada a deposição de propágulos oriundos dos fragmentos adjacentes, o que evidencia a necessidade de implementação de outras técnicas de recuperação para o incremento de propágulos de espécies de classes sucessionais mais avançadas.

Ainda que em baixas densidades, evidenciou-se que tanto na floresta alta de restinga quanto na clareira aberta nessa floresta a chuva de sementes apresenta grande potencial de manutenção e renovação das espécies que se estabelecerão nesses locais, mantendo o fluxo gênico e garantindo a perpetuação da floresta.

\section{AGRADECIMENTOS}

À Sociedade Técnica de Areias para Fundição Ltda. (STAF) por ter permitido a realização deste estudo em sua propriedade; e ao CNPq, pela bolsa concedida.

\section{REFERÊNCIAS BIBLIOGRÁFICAS}

ALVES, L.F.; METZGER, J.P. A regeneração florestal em áreas de floresta secundária na reserva Florestal do Morro Grande, Cotia, SP. Biotaneotropica, v.6, n.2, p. 1-26, 2006.

ARAÚJO, D.S.D.; LACERDA, L. A natureza das restingas. Ciência Hoje, v.6, p. 42-48, 1987.

ARAÚJO, D.S.D.. Comunidades vegetais. In: LACERDA, L.D.; ARAÚJO, D.S.D e CERQUEIRA, R. (Ed.) Restingas: origem, estrutura e processos. Niterói: CEUFF, 1984. p.157-158.

BARBOSA, K.C.; PIZO, M.A. Seed Rain and Seed Limitation in a Planted Gallery Forest in Brazil.

Restoration Ecology, v. 14, n. 4, p. 504-515, 2006.

BUDOWSKY, G. Distribution of tropical American rain forest species in the light of sucession process. Turrialba, v 15, p. 40-42, 1965.

CARRASCO, P.G. Produção de mudas de espécies florestais de restinga, com base em estudos florísticos e fitossociológicos, visando a recuperação de áreas degradadas, em Ilha Comprida - SP. 2003. 186p. Tese (Doutorado em Biociências) - Universidade Estadual Paulista, Rio Claro, SP, 2003.

CEPAGRI. Centro de Pesquisas meteorológicas e climáticas aplicadas à agricultura. <http:// www.cpa.unicamp.br/o-cepagri.html

CESAR, O. \& MONTEIRO, R. Florística e fitossociologia de uma floresta de restinga em Picinguaba (Parque Estadual da Serra do Mar), Município de Ubatuba-SP. Naturalia, v.20, p.89-105, 1995.

CONAMA. Resolução CONAMA 007/96. CONAMA, Brasília, DF, 23 jul.1996.

CUNHA, L. O.; FONTES, M. A. L., OLIVEIRA, A. D. de; OLIVEIRA-FILHO, A. T. de. Análise Multivariada da Vegetação como Ferramenta para Avaliar a Reabilitação de Dunas Litorâneas Mineradas em Mataraca, Paraíba, Brasil.

Revista Árvore. Viçosa, MG, v.27, n.4, p.503-515, 2003. 
DUNCAN, R. S.; CHAPMAM, C. A. Seed dispersal and potential forest sucession in abandoned agriculture in Tropical Africa. Ecologycal Applications, v. 9, n. 3, p. 9981008, 1999.

GUEDES e SILVA, D. C.; BARBOSA, L.M. e MARTINS, S.E. Densidade e composição florística do banco de sementes do solo de fragmentos de Floresta de Restinga no Município de bertioga-SP. Ver. Inst. Flor, v. 17, p. 143-150, 2005.

HARPER, J. L. Population biology of plants. London: Academic Press, 1977. 892p

HOWE, H.; SMALLWOOD, J. Ecology of seed dispersal. Annual Review of Ecology and Systematics, n. 13, p. 201-228, 1982.

JESUS, F. M.; Pivello, VR; Geraldo Franco; Sérgio Tadeu. Seed rain in the Atlantic Rain Forest fragments, Caucaia do Alto, SP. In: Frontiers in Tropical Biology and Conservation - ATBC, 2005, Uberlândia. Frontiers in Tropical Biology and Conservation - ATBC, 2005.

KENT, M.; COKER, P. Vegetation description and analysis - a practical approach. London: Belhaven Press, 1992.

LOPES, E. Formações Florestais de Planície Costeira e Baixa Encosta e sua relação com o substrato geológico das Bacias dos Rios Itaguaré e Guaratuba (Bertioga, SP). 2007. 126p Dissertação. Instituto de Botânica da Secretaria do Meio Ambiente do Estado de São Paulo. Biodiversidade Vegetal e Meio Ambiente- Plantas vasculares, 2007.

MAGURRAN, A. E. Ecological diversity and its measurement. Princeton: Princeton University Press, 1988. 179p.

MANTOVANI, W. A região litorânea paulista. In: Barbosa, L. M. (Coord.) Anais do Workshop sobre recuperação de areas degradadas da Serra da Mar e formações litorâneas. 2000. Secretaria do Meio ambiente, São Paulo. 2000. p.33-41.

MARTÍNEZ-RAMOS, M.; SOTO-CASTRO, A. Seed rain and advanced regeneration in tropical rain forest. Vegetatio, v. 107/108, p. 299-318, 1993.
MARTINS, F. R. Estrutura de uma floresta mesófila. Campinas: Editora da UNICAMP, 1991. v. 1, 246 p.

MORELLATO, L. P. C.; LEITÃO FILHO, H. F. Padrões de frutificação e dispersão na Serra da Japi. 1992. In: Morellato, L. P. C. (Org.).

História natural da Serra do Japi: ecologia e preservação de uma área florestal no Sudeste do Brasil. UNICAMP/FAPESP, Campinas. 1992. p. 112-141.

MUELLER-DUMBOIS, D. e ELLENBERG, H. Aims and methods of vegetation ecology. New York: Jonh Willey \& Sons. 1974. 574p.

OLIVEIRA, R.J.; MANTOVANI, W. E MELO, M.M.R.F. Estrutura do componente arbustivoarbóreo da Floresta Atlântica de Encosta, Peruíbe, SP. Acta Botânica Brasílica, v.15, n. 3, p.391- 412, 2001.

PIELOU, E. C. Ecologycal diversity. Nem York: Jonh Wiley \& Sons, 1975. 165p.

PIJL, L. VAN DER. Principles of dispersal in higher plants. Berlim: Springer, 1972. 162p.

PIVELLO, V. R.; PETENON, D.; JESUS, F.M.; MEIRELLES, S.T.; VIDAL, M.M.; ALONSO, R.A.S.; FRANCO, G.A.D.C. E METZGER, J.P. Chuva de sementes em fragmentos de Floresta Atlântica (São Paulo, SP, Brasil), sob diferentes situações de conectividade, estrutura florestal e proximidade da borda. Acta Botânica Brasílica, v.20, n.4, p.845-859, 2006.

REIS-DUARTE, R. M. Estrutura da Floresta de restinga do Parque Estadual da Ilha Anchieta (SP): bases para promover o enriquecimento com espécies arbóreas nativas em solos alterados. 2004. 258p. Tese (Doutorado em Biologia Vegetal), Universidade Estadual Paulista - UNESP, Rio Claro, 2004.

RODRIGUES, R. R. (coord). Workshop sobre recuperação de áreas degradadas e formações florestais litorâneas. Anais. São Paulo, SMA, 199 p, 2000.

Revista Árvore, Viçosa-MG, v.34, n.5, p.815-824, 2010 
SÃO PAULO (Estado). Manual de Reconhecimento de espécies vegetais da restinga do Estado de São Paulo. Secretaria do Meio Ambiente, Departamento Estadual de Proteção de Recursos Naturais DEPRN, São Paulo. 2005.

SACRAMENTO, A. C.; ZICKEL, C. S.; ALMEIDA JR, E. B. Aspectos Florísticos da Vegetação de Restinga no Litoral de Pernambuco. Revista Árvore, Viçosa-MG, v.31, n.6, p.1121-1130, 2007.

SCARANO, F.R. Structure, Function na Floristic Relationships of Plant Communities in Stressful Habitats Marginal to the Brazilian Atlantic Rainforest. Annals of Botany, v.90, p.517-524, 2002.

SCARANO, F.R. Prioridades para Conservação: a Linha Tênue Que Separa Teorias e Dogmas. In: Carlos Frederico Duarte Rocha, Helena Godoy Bergallo, Monique Van Sluys e Maria Alice Santos Alves. Biologia da Conservação:

Essências. RIMA. São Carlos. 2006, p.23-39.

SCHERER, A.; MARASCHIN-SILVA, F. E BAPTISTA, L.R. DE. Florística e estrutura do componente arbóreo de matas de Restinga arenosa no Parque Estadual de Itapuã, RS, Brasil. Acta Botânica Brasílica, v.19, n.4, p.717-726, 2005.

SILVA, C. R. DA. Fitossociologia e avaliação da chuva de sementes em uma área de Floresta Alta de Restinga, em Ilha Comprida- SP. 2006. 95p. Dissertação. Instituto de Botânica da Secretaria do Meio Ambiente do Estado de São Paulo. Biodiversidade Vegetal e Meio Ambiente- Plantas vasculares, 2006.
SOUZA, S. C. P. M. ; RODRIGUES, Ricardo Ribeiro . A chuva de sementes em áreas antropizadas no Parque Estadual de Jurupará, Ibiúna, São Paulo. In: VI Simpósio Nacional e Congresso Latino-

Americano sobre recuperação de áreas degradadas, 2005, Curitiba. Anais do VI Seminário Brasileiro sobre recuperação de áreas degradada, Congresso Latino-Americano sobre recuperação de áreas degradadas. 2005. p. 259-268.

SOUZA, C. R. G; HIRUMA, S. T.; SALLUN, A. E. M.; RIBEIRO, R. R. e SOBRINHO, A. M. A.

"Restinga": Conceitos e Empregos do Termo no Brasil e Implicações na Legislação Ambiental. São Paulo: Instituto Geológico. 2008, 104p.

SUGIYAMA, M. Estudo de florestas da restinga da Ilha do Cardoso, Cananéia, São Paulo, Brasil. Boletim do Instituto de Botânica, n.11, p. 119-159, 1998.

TABARELLI, M. ; MANTOVANI, W. Ocupacao de Clareiras Naturais Na Floresta Na Serra da CantareiraSp. Naturalia, São Paulo, v. 22, n. 1, p. 89-102, 1997.

TALORA, D.C. \& MORELLATO, P.C. Fenologia de espécies arbóreas em floresta de planície litorânea do sudeste do Brasil. Revista brasileira Botanica. v.23. n.1. p.13-26, 2000.

TESSLER, M.G.\& GOYA, S.C. Conditioning factors of coastal processes in the Brazilian Coastal Area. Revista do Departamento de Geografia, n. 17, p. 11-23, 2005.

VIEIRA, D. C. M.; GANDOLFI, S. Chuva de sementes e regeneração natural sob três espécies arbóreas em uma floresta em processo de restauração. Revista Brasileira de Botânica, São Paulo, v. 29, n. 4, 2006. 